\title{
Silent Myocardial Ischemia Screening in Patients With Diabetes Mellitus
}

\begin{abstract}
The prevalence of diabetes mellitus is fairly increasing, especially in the developing countries. Diabetes is a major cardiovascular risk factor; it often leads to severe cardiovascular complications, and coronary artery disease (CAD) is the main cause of death in diabetic patients. Silent myocardial ischemia (SMI) is more frequent in diabetic patients. The progress made in detection and treatment of CAD allows reconsidering the screening of SMI, in the hope that early CAD diagnosis leads to a more effective therapy and the decrease of cardiovascular complications and mortality. However, the benefit of systematic SMI screening remains discussed. Current guidelines recommend screening SMI in asymptomatic diabetic patients selected for high cardiovascular risk (i.e. with two or more other cardiovascular risk factors, or peripheral or carotid arterial disease, or proteinuria). ECG stress test can be recommended in first intention if maximal heart rate can be achieved. For patient with inconclusive ECG stress test, myocardial scintigraphy seems more accurate than stress echocardiography. Coronary angiogram should be performed in case of positive stress test. Further evaluations of systematic screening have to be conducted on broad randomized trial. (Arq Bras Endocrinol Metab 2007;51/2:285-293)
\end{abstract}

Keywords: Diabetes mellitus; Silent myocardial ischemia; Coronary artery disease; Single photon emission computed tomography; Stress echocardiography

\section{RESUMO}

\section{Rastreamento da isquemia Miorcárdica Silenciosa em Pacientes com Diabetes Mellitus.}

A prevalência do diabetes mellitus está crescendo de forma importante, em especial nos países em desenvolvimento. A isquemia miocárdica silenciosa (IMS) é mais freqüente em diabéticos. Ainda, o diabetes é um forte fator de risco cardiovascular, sendo que, com freqüência, leva a graves complicações cardiovasculares. A doença arterial coronariana (DAC) é a principal causa de morte em pacientes com diabetes. Os progressos alcançados na detecção e tratamento da DAC permitem considerar o rastreamento da IMS, na expectativa de que o diagnóstico precoce levaria a terapias mais efetivas e a redução das complicações cardiovasculares e da mortalidade. Entretanto, o benefício do rastreamento sistemático da IMS permanece discutível. Recomendações atuais sugerem o rastreamento em pacientes diabéticos assintomáticos selecionados por possuírem alto risco cardiovascular (ex. dois ou mais marcadores de risco, ou doença arterial periférica ou doença arterial das carótidas, ou proteinúria). O ECG de stress pode ser considerado como teste inicial se a freqüência cardíaca máxima for atingida. Nos pacientes com este teste inconclusivo, a cintilografia do miocárdio parece ter mais acurácia diagnóstica do que o ecocardiograma de stress. A angiografia coronariana deve ser indicada em casos com teste de stress positivo. Avaliações futuras do rastreamento sistemático devem ser conduzidas em estudos randomizados multicênctricos. (Arq Bras Endocrinol Metab 2007;51/2:285-293)

Descritores: Diabetes mellitus; Isquemia miocárdica silenciosa; Doença arterial coronariana; Ecocoardiografia de stress; Cintilografia do miocárdio

\section{atualização}

\author{
OLIVIER BARTHELEMY \\ Claude Le Feuvre \\ JOSÉ TIMSIT
}

Institute of Cardiology, Hospital Group Pitié-Salpêtrière (OB \& CLF), and Service of Diabetology and INSERM U561, Hospital Center Cochin (JT), APHP, Université Paris 5, Paris, France.
Recebido em 16/10/06 Aceito em 23/10/06 
$\mathrm{T}$ HE PREVALENCE OF Diabetes Mellitus (DM) is fairly increasing. More than 170 million patients have DM all over the world, and the World Health Organisation (WHO) forecast projects twice as many patients in 2025 (1). DM is a major cardiovascular risk factor, and it often leads to severe cardiovascular complications (peripheral arterial disease, myocardial infarction, stroke). Coronary artery disease (CAD) is the main cause of death in patients with DM and accounts for more than $75 \%$ of deaths. Silent myocardial ischemia $(\mathrm{SMI})$ is more frequent in diabetic patients leading to a delayed diagnosis and a more advanced stage of the CAD at the time of the diagnosis.

The progress in detection and treatment of CAD allows us to reconsider the screening of SMI, with the hope of an early CAD diagnosis, which will lead to a more effective therapy and the decrease of cardiovascular complications and mortality. Different screening guidelines have been edited by national societies of cardiology and/or diabetology in order to help physicians' decisions. But as far as today, there is no clear evidence taken from large randomized prospective trials of a prognostic benefit from systematic SMI screening in the diabetic population. Questions remain without clear answers: Which asymptomatic diabetic patients should be screened (according to the cardiovascular risk level)? Which is the more appropriated non-invasive test to determine the presence of CAD? Is the screening of SMI cost-effective? Which global strategy to take when facing an asymptomatic diabetic patient?

\section{WHAT WE KNOW}

\section{Diabetes mellitus}

Population increase and ageing, urbanization and life style change with obesity increase and physical activity decrease are associated with the increase of diabetes mellitus prevalence. In 2000, 2.8\% of the world population are diabetic and the non-diagnosed diabetic population reaches $25 \%$ more, at least according to estimations (2). Type 2 diabetes represents $90 \%$ of the cases. The prognosis of DM is driven by cardiovascular complications, which occurs more often (50 to $200 \%$ increase of cardiovascular events frequency) and are more severe than in non-diabetic patients (3). They participate in the shortening of life expectancy, by 8 years for 55 - to 64 -year-old diabetics and 4 years for the elderly (4). Death results from a cardiovascular cause in more than $75 \%$ in diabetic population $(5,6)$.
Myocardial infarction could be responsible for 30\% of the deaths and post-infarction death occurs twice as more (1). It has been suggested that cardiovascular death rate of diabetic patients without prior myocardial infarction could be similar to that of non-diabetic patients with prior myocardial infarction (7). However, this observation remains very controversial. Patients with acute myocardial infarction (MI) are often asymptomatic or presenting with atypical symptoms. Even if reperfusion therapy (thrombolysis, percutaneous coronary intervention) seems to be effective in the same way for diabetic patients as for non-diabetic ones, post-MI complications and death are more frequent in the diabetic population. After coronary revascularization, cardiovascular events occur more often in patients with DM: 3.5- and 2-fold mortality rates respectively after percutaneous coronary intervention or coronary bypass graft surgery (8).

Diabetes seems to increase the risk of cardiac events of other risk factors since with an equal number of cardiovascular risk factors the diabetic population has a superior cardiovascular death rate (9).

\section{Silent myocardial ischemia (SMI)}

Myocardial ischemia is defined as a transient and reversible decrease in oxygen contribution to myocardium, leading to an inadequacy of contribution/need ratio. It is responsible for the following events: initially haemodynamic (elevated end diastolic left ventricular pressure then kinetic change), then metabolic (lactates production), electric (repolarisation change) and clinic (chest pain). Silent myocardial ischemia is characterized by the lack of the clinical step.

Three types of SMI can be differentiated according to Cohn classification (10): Type I: totally asymptomatic patients without prior cardiovascular events. Type II: totally asymptomatic patients with prior myocardial infarction. Type III: Patients having symptomatic and also asymptomatic ischemia. Only type I will be considered in this review.

Several mechanisms are integrated in the SMI genesis. Endothelial dysfunction secondary to DM may play a role, leading to an inappropriate coronary flow response to increasing myocardial metabolic needs (coronary vascular tone abnormality). It is also due to an increased pain feeling threshold in diabetic patients, probably secondary to an elevated betaendorphins rate. These two abnormalities are associated with an impaired autonomic nervous system. The prevalence of SMI in the diabetic population is very variable in the different studies, ranging from $12 \%$ to almost $57 \%(11,12)$. It is 3 to 6 fold higher than in 
asymptomatic non-diabetic population (13). This wide prevalence variation of SMI in patients with DM is in part due to the population selection, which is not homogeneous in regard of the cardiovascular risk status. This variability underlines the difficulty to have a cost-effective screening and the absolute necessity to define a high cardiovascular risk asymptomatic diabetic population likely to fully benefit from this screening. Silent myocardial ischemia is associated with a poor prognosis, with a 3- to 4 -fold increase of cardiovascular events rate in case of SMI (12).

However, there is no strong correlation between SMI and significant CAD. In fact, significant coronary artery stenosis is found only in 30 to $60 \%$ diabetic patients with SMI $(14,15)$. These can be explained by the endothelial dysfunction encounter during diabetes: intra coronary flow Doppler measurements have demonstrated a reduced Coronary Flow Reserve in more than $50 \%$ of patients with SMI and angiographically normal coronary arteries (16) (figure 1).

\section{Coronary artery disease (CAD)}

Coronary artery disease is characterized by its severity in the diabetic population with more frequent multivessel disease, and diffuse, calcified and distal lesions (17). Its asymptomatic feature explains in part this severity due to a delayed diagnostic. There's also a specific atherosclerosis feature in diabetic patients due to:

- Lipid profile abnormalities with increased oxidized LDL and an increase in the concentration of small and dense LDL particles. It participates in the high vulnerability of diabetic atheroma plaque made up of a rich lipid core and a thin chap;

- Haemostasis abnormalities with an increasing platelet aggregation (high ADP sensitivity, high thrombin sensitivity, high thromboxane A2 production; von Willebrand Factor increase) and a reduced physiological fibrinolysis (PAI-1 increase);

- Impaired vascular tone, local inflammation.

It underlines the need to detect CAD in diabetic patients, very early before symptoms occur, at a time when patients can benefit from revascularization.

\section{EXPECTED BENEFIT OF THE SCREENING}

The benefit of early and systematic SMI detection in the diabetic population has not yet been proven. However, the positive results of CAD therapy for diabetic patients and of SMI treatment for high cardiovascular risk diabetic or non-diabetic patients tend to suggest it.

\section{Reinforced prevention}

It is now well established that diabetic patients benefit from an intensive cardiovascular prevention. And silent myocardial ischemia leads to consider diabetes as an indication for secondary prevention.

We must first insist on the absolute necessity of smoking cessation, physical activity and the so-called "Mediterranean diet".

For more than 10 years, lipid-lowering therapies, with statins at foreground, have demonstrated their spectacular effectiveness in the prevention of cardiovascular morbid-mortality. Statins benefit is demonstrated in secondary prevention for hypercholesterolemia diabetic patients with a $55 \%$ relative risk reduction of cardiovascular events with Simvastatin. These benefits are also shown for normocholesterolemia diabetic patients, with a $25 \%$ relative risk
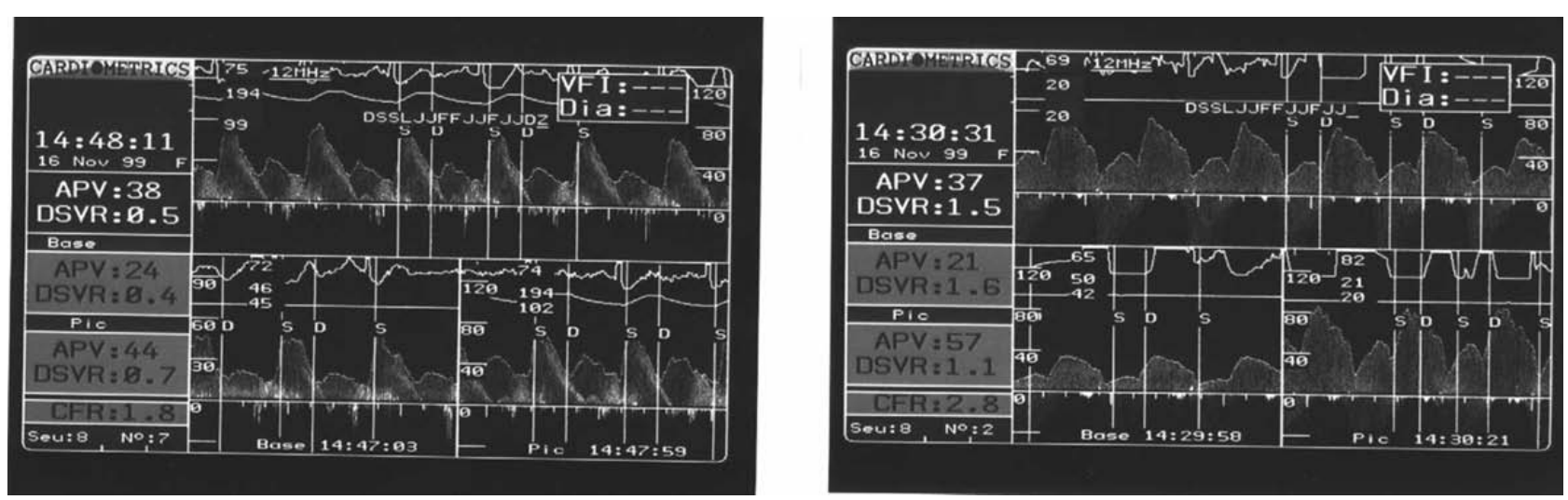

Figure 1. Intra-coronary Doppler imaging assessing coronary flow reserve (CFR) after adenosine in a diabetic patient with lateral silent myocardial ischemia at SPECT: CFR is reduced in the left circumflex artery (left picture) and normal in the left anterior descending artery (right picture). 
reduction with Pravastatin $(18,19)$. These results are confirmed by the wide Heart Protection Study (20536 pts), with a similar cardiovascular risk reduction in diabetic patients than non-diabetics independently of the LDL cholesterol level (20). The benefit is also demonstrated in primary prevention with a $33 \%$ relative risk reduction. Today, other lipid-lowering therapies haven't shown such benefit: there is no significant benefit on the rate of cardiovascular events with the use of Fenofibrate (21), and Ezetimibe is still under evaluation.

NCEP ATP III guidelines, as European guidelines (the SCORE project) when microalbuminuria is present, consider diabetes as an equivalent to coronary heart disease, meaning that LDL cholesterol goal for asymptomatic diabetic patients should be the same as for non-diabetic patients with prior cardiovascular events (LDL cholesterol $<\mathrm{lg} / \mathrm{l}$ ), with a threshold for drug therapy intervention of $1.3 \mathrm{~g} / 1(22,23)$.

High blood pressure (HBP) control has also shown its effectiveness. UKPDS 38 proved the benefit of tight blood pressure control for the reduction of macroangiopathy complications with a $32 \%$ relative risk reduction secondary to a $10 \mathrm{mmHg}$ and $5 \mathrm{mmHg}$, respectively, decrease of systolic and diastolic blood pressure (24). Angiotensin-converting-enzyme inhibitor seems to be the therapy of choice, especially in association with microalbuminuria and left ventricular hypertrophy. Treating 1,000 high-risk diabetic patients during 4 years with Ramipril permits to avoid approximately 150 events for 70 patients (25). This drug class has also shown its ability to prevent renal failure outcome.

Current recommendations define a blood pressure goal $<130 / 80 \mathrm{mmHg}$ for cardiovascular prevention in diabetic population $(22,26)$.

Improvement of diabetic prognosis by intensive blood-glucose control remains discussed. The UKPDS has shown a clear benefit of glycaemia control for microangiopathy complications prevention but no significant benefit for macroangiopathy reduction despite an increase of $11 \%$ in cardiovascular events rate at 10 years for each increase of HbAlc of $1 \%$ (27). However, in the metformin arm of this study, a clear reduction of the risk of myocardial infarction and of diabetes related mortality was observed (28). Among new anti-diabetic therapy, treatment with pioglitazone, a thiazolidinedione, has demonstrated a reduction in the rate of cardiovascular events but with an increase in the rate of heart failure events probably due to fluid retention $(29,30)$.

Aspirin has also shown its effectiveness to prevent cardiovascular events. In primary prevention, aspirin use leads to a $17 \%$ reduction rate of myocardial infarction versus placebo without any difference in mortality rate $(31)$.

\section{Anti-ischemia therapy}

Silent myocardial ischemia leads to the introduction of an anti-ischemia therapy. In this setting, beta-blockers seem to be effective as shown in the ACIP study with a significant reduction of death, MI and repeated hospitalization when ischemia is controlled by therapy (32). But this benefit remains less important than that obtained by revascularization strategy. Major cardiovascular events (MACE) reduction is also shown in secondary prevention with beta-blockers. Also, angiotensin-converting enzyme inhibitors decrease significantly the recurrence of cardiovascular events (33).

\section{Revascularization}

Until today revascularization of asymptomatic type 2 diabetic subjects remains discussed. In fact, there is no clear evidence on wide randomized trial of its benefit. BARI-2 trial, comparing revascularization versus medical therapy in diabetic patients with SMI, could answer the question but is still in process. Nevertheless, it is logical to propose myocardial revascularization in case of large ischemia independently of symptoms. Myocardial revascularization by surgery seems to be more effective than anti-ischemia therapy for prior CAD patients with SMI in ACIP study (32). CASS study showed a superiority of surgery on medical treatment in diabetic patients with 3-vessel disease and SMI at ECG stress test. And we know that coronary artery bypass graft $(\mathrm{CABG})$ is effective in terms of mortality for stable symptomatic patients with left main coronary or 3 vessels disease and left ventricular dysfunction (34). Percutaneous coronary intervention (PCI) has no proven benefit in terms of mortality in single vessel CAD but improves quality of life. Sevenyear follow-up of BARI trial shows a weaker mortality rate for diabetic patients with CABG $24.5 \%$ vs. PCI (with balloon alone) 44\%, especially when internal mammary artery was used (8). CABG also shows its superiority on PCI with bare metal stent for type 2 diabetics with multivessel disease, essentially due to a lower target vessel revascularization rate in the surgery group (35). Since the development of drug eluting stent, binary restenosis rate decreased widely after PCI in diabetic patients: target lesion revascularization reduced from $22 \%$ to $7.2 \%$ with Cypher in SIRIUS, $15 \%$ vs. $5.3 \%$ with Taxus in TAXUS IV, $15.2 \%$ vs. $7.5 \%$ with Endeavor in ENDEAVOR II trial, approaching non-diabetic restenosis rate. Non-randomized data 
concerning the use of drug eluting stent (DES) vs. surgery in multivessel disease diabetic patients demonstrate its effectiveness in terms of MACE and cost (36). Two large randomized studies (FREEDOM, SYNTAX) that aim at confirming these results are currently in progress.

In practice, when a PCI is indicated, DES should be preferred because of its proven lower restenosis rate, and intra-venous antiplatelet agents, especially abciximab, should be widely used because of its proven lower mortality rate (37).

\section{SCREENING METHODS}

\section{Which patients?}

Despite a high cardiovascular event rate in diabetic population, all the type 2 diabetic patients do not have SMI. Moreover, SMI detection does not systematically lead to CAD. Wide systematic screening for SMI cannot be recommended in regard to its moderate prevalence and the high cost of non-invasive stress test. This is the reason why a high cardiovascular risk asymptomatic diabetic population should be defined, in order to fully benefit from SMI screening. According to these considerations, national societies edited guidelines in order to help practitioner to select highrisk subjects likely to fully benefit from SMI and CAD detection. American Diabetes Association (ADA) consensus conference summarizes the indications for CAD testing in diabetic patients: two other cardiovascular risk factors (including microalbuminuria), or another atherosclerosis location or evidence of ischemia on resting ECG are the main warranted conditions to start the SMI screening (38) (table 1). Guidelines edited by the Société Française de Cardiologie / Association de Langue Française pour l'Etude du DIAbète et des Maladies métaboliques (SFC/ ALFEDIAM) are very similar and recommend SMI screening for asymptomatic patients with type $2 \mathrm{DM}$ with peripheral or carotid arterial disease, proteinuria or $>60$ years old and at least two others cardiovascular risk factors (39) (table 2). Those guidelines are driven by current knowledge concerning global cardio-

Table 1. ADA Guidelines 1998 - Indications for cardiac testing in diabetic patients.

Testing for CAD is warranted in patients with the following:
1. Typical or atypical cardiac symptoms
2. Resting electrocardiogram suggestive of ischemia or infarction
3. Peripheral or carotid occlusive arterial disease
4. Sedentary lifestyle, age $\geq 35$ years, and plans to begin a vigorous exercise program
5. Two or more of the risk factors listed below in addition to diabetes:
a. Total cholesterol $\geq 2.4 \mathrm{~g} / \mathrm{l}, \mathrm{LDL}$ cholesterol $\geq 1.6 \mathrm{~g} / \mathrm{l}$, or $\mathrm{HDL}$ cholesterol $<0.35 \mathrm{~g} / \mathrm{l}$
b. Blood pressure $>140 / 90 \mathrm{mmHg}$
c. Smoking
d. Family history of premature CAD
e. Positive micro/macroalbuminuria test

Table 2. SFC/ALFEDIAM guidelines 2004.

SMI screening is indicated for high risk asymptomatic type II diabetic patients defined by:

1. $>60$ years old or diabetes known more than 10 years before and with at least 2 other cardiovascular risk factors: a. Total cholesterol $>2.5 \mathrm{~g} / \mathrm{l}$, LDL cholesterol $>1.6 \mathrm{~g} / \mathrm{l}$, or HDL cholesterol $<0.35 \mathrm{~g} / \mathrm{l}$, Triglycerides $>2 \mathrm{~g} / \mathrm{l}$ or lipid lowering therapy

b. Blood pressure $>140 / 90 \mathrm{mmHg}$ or blood pressure lowering therapy

c. Current smoker or during the last 3 years

d. Family history of premature CAD (before 60 years) in first degree relationship

2. Peripheral or carotid arterial disease

3. Proteinuria

4. Microalbuminuria and at least 2 others cardiovascular risk factors independently of the age

5. Sedentary lifestyle, age $\geq 45$ years, and plans to begin a vigorous exercise program 
vascular risk and their modifiable determinants and also the Bayes' theorem stipulating that false-positive rate of a screening test is inversely proportional to disease prevalence. Performing systematic or low-risk population screening, in addition to be unfeasible, would be inefficient. Past ALFEDIAM guidelines (1995), recommending screening for asymptomatic patients with type $2 \mathrm{DM}$ with only one associated risk factor, lead to a cost-ineffective screening with less than $10 \%$ CAD detection (40). This is the reason why selected population is now proposed for SMI screening: indeed, SMI prevalence is higher in $>60$-year-old patients and its prognostic value is worse. We also know that diabetes is often associated with other cardiovascular risk factors and increase their cardiovascular consequences. Other atherosclerotic location is of bad prognosis too in asymptomatic diabetic patients leading to increased SMI and cardiovascular event rates $(41)$. In the same way, an increased microalbuminuria predicts a high cardiovascular event rate with a two-time earlier mortality rate (42).

\section{Which stress test?}

After defining a selected high-risk diabetic population for cardiovascular events, remains the choice of the more appropriate test to detect SMI and CAD in such patients.

Resting ECG is essential yearly for type 2 diabetic patients because of its great pejorative prognostic value in case of abnormalities, which must lead to further exploration. But normal ECG has a very poor negative predictive value in asymptomatic type 2 diabetic patients leading to misunderstand severe coronary multivessel disease (43). So that ECG can't be recommended as the only screening test for high-risk patients. Twenty-four-hour ambulatory monitoring of ST segment changes has also a poor sensitivity and a poor specificity, but could improve with future upgrading (ST segment change analysis).

Treadmill stress test is widely used for CAD detection in the general population because of its easiness to perform, its relative good predictive value and its low cost. In diabetic patients ECG stress test has an $87 \%$ negative predictive value with $75 \%$ specificity (44). Although this imperfect efficiency, exercise test is still reliable for detecting severe CAD (left main coronary or 3-vessel involvement) possibly engaging vital prognosis. But this reliability is linked to the ability to perform an adequate effort, in order to reach almost $85 \%$ of the maximal heart rate. This is not ever possible in this particular population because of a high rate of obesity, peripheral vessel disease and other co-mor- bidities. Accordingly, all cardiac medications (e.g., beta-blockers, nitrates) able to delay the time of onset of ischemia have to be stopped before the test. Selecting diabetic patients able to perform a maximal stress test could be recommended in first intention in regard of the cost.

Stress single-photon emission computed tomography (SPECT) with thallium or MIBI provides multiple information like ischemia location and extension, left ventricular function helping physicians in appreciating its severity. Stress test can be coupled with pharmacologic test (dipyridamole, adenosine). SPECT has a better sensitivity $(80-90 \%)$ and specificity $(75-90 \%)$ rate than ECG stress test for diabetics (44). Its main interest is represented by its high negative predictive value (95\%). In the general population with risk factors or prior CAD, a negative SPECT predicts a less than $1 \%$ death or myocardial infarction rate per year (45). In asymptomatic diabetic population, cardiovascular events rate at five years is significantly higher in case of abnormal SPECT $19.2 \%$ vs. $1.9 \%$ in absence of ischemia (46). A myocardial ischemia involving more than $10 \%$ of left ventricle must lead to a coronary angiogram (46). For all this reason SPECT seems to be a test of choice for SMI screening for asymptomatic diabetic patients unable to perform an adequate exercise ECG stress test.

Stress echocardiography (SE) during exercise or pharmacologic stress (e.g. with Dobutamine) is another alternative for SMI screening. SE detects wall motion abnormalities during stress and also provides information on ischemia intensity, left ventricular function. In asymptomatic diabetic patients, sensitivity and specificity are respectively $81 \%$ and $85 \%(47)$. Three-year follow-up of asymptomatic diabetic patients with a negative SE shows a $2 \%$ major cardiovascular event rate. Thus, SE has quite similar diagnostic and prognostic accuracy than SPECT and is costless. Nevertheless, in our experiment SE remains less feasible in that particular population with less than $80 \%$ satisfactory interpretable test, due especially to poor echogenicity (high obesity rate) and inability to achieve maximal stress test (in spite of dobutamine and atropine) (16).

Coronary computed tomography (CT) provides a non-invasive coronary angiogram (figure 2). This is a morphologic exam in evaluation process providing no information concerning ischemia. Its diagnostic accuracy has not yet been well defined but its quick upgrading could lead to becoming a test of choice in CAD screening. Nevertheless, some important limits remain: contrast agent nephropathy 


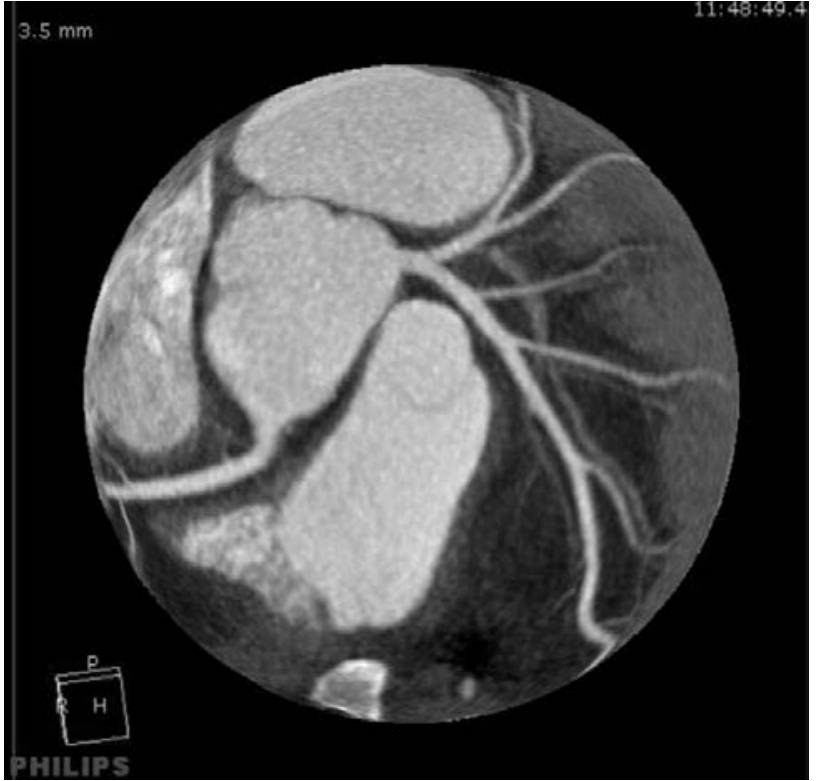

Figure 2. Non-invasive coronary angiogram performed by coronary 64-row multidetector computed tomography.

(iodine agent), high $\mathrm{x}$-ray patient exposure (two times more important than coronary angiogram), coronary calcifications and vessel distal bed sub-optimal viewing leading to incomplete results, imprecise coronary narrowing quantification. CT includes the risk of a useless increasing indication of coronary angiogram due to this morphologic but no functional assessment of coronary arteries.

Magnetic resonance imaging (MRI) also provides a non-invasive coronary angiogram, with a lot of functional (myocardial perfusion...) and anatomical (ventricular function, wall motion) information. This is a non-irradiating imaging, and includes no risk of contrast-induced nephropathy. But it seems today to be less accurate than CT for coronary stenosis diagnosis, particularly in vessel distal bed analysis. Nevertheless, coupling a non-invasive imaging of coronary arteries with a pharmacological stress test assessing the intensity and location of ischemia could set MRI up as the gold standard for CAD detection in the future.

Moreover, in the future, MRI could also provide information on atherosclerosis plaque vulnerability (according to its anatomical feature: thin fibrous cap overlying a lipid-rich core and macrophage activity).

\section{SCREENING STRATEGY (figure 3)}

Annual clinical check-up focused on cardiovascular complications should be recommended for type 2 diabetic patients. An attentive clinical symptom search should be performed with particular attention for atypical symptom feature of CAD (e.g. blockpnea, epigastralgia). It can possibly lead to direct SMI screening, particularly when stress linked. Major cardiovascular risk factors have to be screened (lipid profile, blood pressure, tobacco consumption, history family of CAD) in order to determine the global CAD risk. Other atherosclerotic locations have to be searched [history of claudication or (transient) stroke, diminished or abolished limb pulse, carotidal murmur] and confirmed with ultrasound testing. Proteinuria and microalbuminuria should be annually measured as ECG performed. This annual clinical, biological and ECG check-up allows physicians to stratify the cardiovascular risk for asymptomatic diabetic patients.

According to SFC/ALFEDIAM guidelines, low-risk patient should be followed every year. High-risk patients should benefit from SMI screening with ECG stress test in first intention for diabetic patients able to perform an adequate exercise, otherwise SPECT or SE can be proposed. In our experiment, SPECT seems to be more feasible than SE. High positive stress test or ischemia involving almost $10 \%$ of left ventricle should lead to coronary angiogram.

Patients with ischemia or infarction on resting ECG should be considered for direct coronary angiogram. Patients without SMI should undergo a new screening every two years.

\section{CONCLUSION}

The benefit of systematic SMI screening remains discussed. Current guidelines recommend screening SMI in selected high cardiovascular risk patients ( $>60$ years and 2 or more others risk cardiovascular factors, peripheral or carotid vessel disease, or proteinuria), more likely to present severe CAD for which coronary revascularization is well established (e.g. left main or multivessel disease). For SMI screening eligible patients, ECG stress test can be recommended in first intention. In case of incapacity to perform an adequate effort, SPECT seems to be more accurate than SE in this particular kind of patients. Further evaluations of systematic screening have to be conducted, like the ongoing DIAD study which plans to follow 1,000 asymptomatic diabetic patients randomized either SMI screening or no testing for CAD (48). 


\section{REFERENCES}

1. King $H$, Aubert RE, Herman WH. Global burden of diabetes, 1995-2005: prevalence, numerical estimates and projection. Diabetes Care 1998;21:1414-31.

2. Wild S, Roglic G, Green A, Sicree R, King H. Global prevalence of diabetes: estimates for the year 2000 and projections for 2030. Diabetes Care 2004;27:1047-53.

3. Kannel WB, McGee DL. Diabetes and cardiovascular disease: the Framingham Study. JAMA 1979;241:2035-8.

4. Gu K, Cowie CC, Harris MI. Mortality in adults with and without diabetes in a national cohort of the US population, 19711993. Diabetes Care 1998;21:1138-45.

5. Grundy SM, Benjamin IJ, Burke GL, Chait A, Eckel RH, Howard BV, et al. Diabetes and cardiovascular disease: a statement for healthcare professionals from the American Heart Association. Circulation 1999;100:1134-46.

6. Jacoby RM, Nesto RW. Acute myocardial infarction in the diabetic patient: pathophysiology, clinical course and prognosis. J Am Coll Cardiol 1992;20:736-44.

7. Haffner SM, Lehto S, Rönnemaa T, Pyörälä K, Laakso M. Mortality from coronary heart disease in subjects with type 2 diabetes and in nondiabetic subjects with and without prior myocardial infarction. N Engl J Med 1998;339:229-34.

8. The Bypass Angioplasty Revascularization Investigation (BARI) Investigators. Seven-year outcome in the Bypass Angioplasty Revascularization Investigation (BARI) by treatment and diabetic status. J Am Coll Cardiol 2000;35:1122-9.

9. Stamler J, Vaccaro O, Neaton JD, Wentworth D. Diabetes, other risk factors and 12-years cardiovascular mortality for men screened in the Multiple Risk Factor Intervention Trial. Diabetes Care 1993;16:434-44.

10. Cohn PF. Should silent ischemia be treated in asymptomatic individuals? Circulation 1990;82149-54.

11. Milan Study on atherosclerosis and diabetes (MiSAD) group. Prevalence of unrecognized silent myocardial ischemia and its association with atherosclerotic risk factors in noninsulindependent diabetes mellitus. Am J Cardiol 1997;79:134-9.

12. Vanzetto G, Halimi S, Hammoud T, Fagret D, Benhamou PY, Cordonnier D, et al. Prediction of cardio-vascular events in clinically selected high-risk NIDDM patients. Diabetes Care 1999:22:19-26.

13. Koïstinen MJ. Prevalence of asymptomatic myocardial ischemia in diabetic subjects. Br Med J 1990;301:92-5.

14. Valensi P, Sachs RN, Lormeau B, Taupin JM, Ouzan J, Blasco $A$, et al. Silent myocardial ischemia and left ventricle hypertrophy in diabetic patients. Diabetes Metab 1997;23:409-16.

15. Jannand-Delenne B, Savin B, Habib G. Silent myocardial ischemia in patients with diabetes. Diabetes Care 1999;22:1396-400.

16. Le Feuvre $C$, Barthélémy $O$, Dubois-Laforgue D, Maunoury Ch, Mogenet A, Baubion N, et al. Stress myocardial scintigraphy and dobutamine echocardiography in the detection of coronary disease in asymptomatic patients with type 2 diabetes. Diabetes Metab 2005;31:135-42.

17. Kip KE, Faxon DP, Detre KM, Yeh W, Kelsey SF, Currier JW. Coronary angioplasty in diabetic patients. The National Heart, Lung, and Blood Institute Percutaneous Transluminal Coronary Angioplasty Registry. Circulation 1996;94:1818-25.

18. Pyörälä K, Pedersen TR, Kjekshus J, Faergeman O, Olsson AG, Thorgeirsson G. Cholesterol lowering with simvastatin improves prognosis of diabetic patients with coronary artery disease: subgroup analysis of the Scandinavian simvastatin survival study. Diabetes Care 1997:20:614-20.

19. Sacks FM, Tonkin AM, Craven T, Pfeffer MA, Shepherd J, Keech $A$, et al. Coronary heart disease in patients with low LDL-cholesterol. Benefit of pravastatin in diabetics and enhanced role for HDL-Cholesterol and triglycerides as risk factors. Circulation 2002:105:1424-8.

20. Heart Protection Study Collaborative Group. MRC/BHF Heart Protection study of cholesterol-lowering with simvastatin in 5963 people with diabetes: a randomized placebo-controlled study. Lancet 2003;361:2005-16.
21. Keech A, Simes RJ, Barter P, Best J, Scott R, Taskinen MR, et al.; FIELD study investigators. Effects of long-term fenofibrate therapy on cardiovascular events in 9795 people with type 2 diabetes mellitus (the FIELD study): randomised controlled trial. Lancet 2005;366:1849-61.

22. Conroy RM, Pyörälä K, Fitzgerald AP, Sans S, Menotti A, De Backer $G$, et al. Estimation of ten-years risk of fatal cardiovascular disease in Europe: The SCORE Project. Eur Heart J 2003;24:897-1003.

23. Executive summary of the third report of the National Cholesterol Education Program (NCEP) Expert Panel on detection, evaluation, and treatment of high blood cholesterol in adults. JAMA 2001;285:2487-97.

24. UK prospective Diabetes Study (UKPDS). Tight blood pressure control and risk of macrovascular and microvascular complications in type 2 diabetes: UKPDS 38. BMJ 1998;317:703-13. (Erratum BMJ 1999;318:29)

25. The Heart Outcomes Prevention Evaluation study investigators. Effects of an angiotensin-converting-enzyme inhibitor ramipril, on cardiovascular events in high-risk patients. $\mathbf{N}$ Engl J Med 2000;342:145-53.

26. Chobanian AV, Bakris GL, Black HR, Cushman WC, Green LA, Izzo JL Jr, et al.; National Heart, Lung, and Blood Institute Joint National Committee on Prevention, Detection, Evaluation, and Treatment of High Blood Pressure; National High Blood Pressure Education Program Coordinating Committee. The Seventh Report of the Joint National Committee on Prevention, Detection, Evaluation, and Treatment of High Blood Pressure: the JNC 7 report. JAMA 2003;289(19):2560-72. (Epub 2003 May 14. Erratum in: JAMA 2003;9:190-7)

27. UK Prospective Diabetes Study (UKPDS) Group. Intensive blood-glucose control with sulphonylureas or insulin compared with conventional treatment and risk of complications in patients with type 2 diabetes (UKPDS 33). Lancet 1998;352:837-53. (Erratum in: Lancet 1999;354 (9178):602)

28. UK Prospective Diabetes Study (UKPDS) Group. Effect of intensive blood-glucose control with metformin on complications in overweight patients with type 2 diabetes (UKPDS 34). Lancet 1998;352:854-65.

29. Charbonnel B, Dormandy J, Erdmann E, Massi-Benedetti M, Skene A; PROactive Study Group. The Prospective Pioglitazone Clinical Trial in Macrovascular Events (PROactive). Diabetes Care 2004;27:1647-53.

30. Le Feuvre C. Cardiovascular effects of rosiglitazone. Presse Med 2004;19:735-45.

31. EDTRS Investigators. Aspirin effects on mortality and morbidity in patients with diabetes mellitus. JAMA 1992;268:1292-300.

32. Rogers WJ, Bourassa MG, Andrews TC, Bertolet BD, Blumenthal RS, Chaitman BR, et al. Asymptomatic Cardiac Ischemia Pilot (ACIP) study: outcome at 1 year for patients with asymptomatic cardiac ischemia randomized to medical therapy or revascularization. The ACIP Investigators. J Am Coll Cardiol 1995;26:594-605.

33. Fox KM; EURopean trial On reduction of cardiac events with Perindopril in stable coronary Artery disease investigators. Efficacy of perindopril in reduction of cardiovascular events among patients with stable coronary artery disease: randomised, double-blind, placebo-controlled, multicentre trial (the EUROPA study). Lancet 2003;362:782-8.

34. Yusuf S, Zucker D, Peduzzi P, Fisher LD, Takaro T, Kennedy JW, et al. Effect of coronary artery bypass graft surgery on survival: overview of 10 -year results from randomised trials by the Coronary Artery Bypass Graft Surgery Trialists Collaboration. Lancet 1994;344:563-70. (Erratum in: Lancet 1994;344:1446)

35. Abizaid A, Costa MA, Centemero M, Abizaid AS, Legrand VM, Limet RV, et al.; Arterial Revascularization Therapy Study Group. Clinical and economic impact of diabetes mellitus on percutaneous and surgical treatment of multivessel coronary disease patients: insights from the Arterial Revascularization Therapy Study (ARTS) trial. Circulation 2001; 104:533-8. 
36. Serruys PW, Lemos PA, van Hout BA; Arterial Revascularisation Therapies Study part II Steering Committee and Investigators. Sirolimus eluting stent implantation for patients with multivessel disease: rationale for the Arterial Revascularisation Therapies Study part II (ARTS II). Heart 2004;90:995-8.

37. Bhatt DL, Marso SP, Lincoff AM, Wolski KE, Ellis SG, Topol EJ. Abciximab reduces mortality in diabetics following percutaneous coronary intervention. J Am Coll Cardiol 2000;35:922-8.

38. Consensus development conference on the diagnosis of coronary heart disease in people with diabetes: 10-11 February 1998, Miami, Florida. American Diabetes Association. Diabetes Care 1998;21:1551-9.

39. Puel J, Valensi P, Vanzetto G, Lassmann-Vague V, Monin JL, Moulin P, et al.; ALFEDIAM; SFC. Identification of myocardial ischemia in the diabetic patient. Joint ALFEDIAM and SFC recommendations. Diabetes Metab 2004;30:3S3-18.

40. Valensi P, Sachs RN, Harfouche B, Lormeau B, Paries J, Cosson $E$, et al. Predictive value of cardiac autonomic neuropathy in diabetic patients with or without silent myocardial ischemia. Diabetes Care 2001;24:339-43.

41. Criqui $M H$, Langer RD, Fronek $A$, Feigelson HS, Klauber MR, McCann TJ, et al. Mortality over a period of 10 years in patients with peripheral arterial disease. N Engl J Med 1992;326:381-6.

42. Dinneen SF, Gerstein HC. The association of microalbuminuria and mortality in non-insulin-dependent diabetes mellitus. A systematic overview of the literature. Arch Intern Med 1997; 157:1413-8.

43. Paillole C, Passa P, Paycha F, Juliard JM, Steg PG, Leblanc H, et al. Non-invasive identification of severe coronary artery disease in patients with long-standing diabetes mellitus. Eur J Med 1992;1:464-8.

44. Paillole C, Ruiz J, Juliard JM, Leblanc H, Gourgon R, Passa P. Detection of coronary artery disease in diabetic patients. Diabetologia 1995;38:726-31.
45. Vanzetto G, Ormezzano O, Fagret D, Comet M, Denis B, Machecourt J. Long-term additive prognostic value of thallium-201 myocardial perfusion imaging over clinical and exercise stress test in low to intermediate risk patients: study in 1137 patients with 6-year follow-up. Circulation 1999;100:1521-7.

46. Faglia E, Favales F, Calia P, Paleari F, Segalini G, Gamba PL, et al.; Milan Study on Atherosclerosis and Diabetes (Mi SAD). Cardiac events in 735 type 2 diabetic patients who underwent screening for unknown asymptomatic coronary heart disease: 5-year follow-up report from the Milan Study on Atherosclerosis and Diabetes (MiSAD). Diabetes Care 2002;25:2032-6.

47. Sozzi FB, Elhendy A, Roelandt JR, van Domburg RT, Schinkel $A F$, Vourvouri EC, et al. Prognostic value of dobutamine stress echocardiography in patients with diabetes. Diabetes Care 2003;26:1074-8.

48. Wackers FJ, Young LH, Inzucchi SE, Chyun DA, Davey JA, Barrett EJ, et al.; Detection of Ischemia in Asymptomatic Diabetics Investigators. Detection of silent myocardial ischemia in asymptomatic diabetic subjects: the DIAD study. Diabetes Care 2004;27:1954-61. (Erratum in: Diabetes Care 2005;28:504)

\section{Endereço para correspondência:}

Olivier Barthelemy

Institut de Cardiologie, Groupe Hospitalier Pitié-Salpêtrière

Assistance Publique - Hôpitaux de Paris

47-83 Bd de I'hôpital, 75651 Paris Cedex 13, France

Fax: +33142163029

E-mail: olivier.barthelemy@psl.aphp.fr 